\title{
Assessment of climate vulnerability in the Norwegian built environment
}

\author{
H. O. Hygen ${ }^{1}$, C. F. Øyen ${ }^{2}$, and A. J. Almås ${ }^{3}$ \\ ${ }^{1}$ Norwegian Meteorological Institute, Postboks 43 Blindern, 0313 Oslo, Norway \\ ${ }^{2}$ SINTEF Building and Infrastructure, Postboks 124 Blindern, 0314 Oslo, Norway \\ ${ }^{3}$ Department of Civil and Transport Engineering, Norwegian University of Science and Technology (NTNU), \\ 7491 Trondheim, Norway
}

Received: 30 December 2010 - Revised: 12 April 2011 - Accepted: 24 May 2011 - Published: 30 May 2011

\begin{abstract}
The main trends expected for the change of Norwegian climate for this century are increasing temperatures, precipitation and wind. This indicates a probable increase of climate-related risks to the Norwegian built environment. Through co-operation between the Norwegian Meteorological Institute and SINTEF Building and Infrastructure, building and climate information have been combined to estimate changes in strain to the built environment due to climate change. The results show that the risk of wood decay will increase for the whole country. Almost two million buildings will be subject to an increase in risk of wood decay from medium to high level. Similar analyses have been performed for other climate indices, demonstrating a clear increase in potential damages due to water and humidity, while frost damage probably will decrease.
\end{abstract}

\section{Introduction}

The Norwegian Meteorological Institute has an archive of daily historic grids of precipitation and temperature with a resolution of $1 \mathrm{~km}$ by $1 \mathrm{~km}$. Downscaling of scenarios for future climate based on global climate models and local climate knowledge has matured to a stage where the same kind of grids are available for various projections of future climate (Engen-Skaugen et al., 2007).

SINTEF Building and Infrastructure and the Norwegian Meteorological Institute have a history ofco-operation. In the research project Climate 2000, one of the projects focused on developing robust building techniques. A series of climate-indices were developed or adapted to the Norwegian climate. Examples of such indices are wood decay (Lis $\varnothing$, 2006), frost decay (Lisø et al., 2007) and driving rain (Rydock et al., 2005).

In 2010 an official Norwegian report on climate-adaptation (NOU, 2010) was launched. As a part of this report the vulnerability of the Norwegian built environment was surveyed. This survey consisted of a multipart approach with a summary of the Norwegian built environment and recorded damages. Another part focussed on climate indices, both historic and future, and the influence on the built environment.

Correspondence to: $\mathrm{H}$. O. Hygen

(hans.olav.hygen@met.no)

\section{Method}

To assess the climate vulnerability of the Norwegian built environment, knowledge of the climate and of the built environment is combined. This work is based on the geolocated daily $1 \mathrm{~km}$ by $1 \mathrm{~km}$ grids of temperature and precipitation, knowledge of geographic distribution of damages and the climate indices developed in the Climate 2000 programme.

Risk of wood decay was first established for the North American continent by Shäffer and adapted to Norway by Lisø et al. (2006). The wood decay index is described in Eq. (1).

Wood Decay $=\frac{\sum_{\text {January }}^{\text {December }}\left(T_{\text {mean }}-2\right)(D-3)}{16.7}$

$T_{\text {mean }}$ is the monthly mean temperature and $D$ is the number of days per month with more than $0.254 \mathrm{~mm}$ (i.e. $0.01 \mathrm{inch}$ ) precipitation.

The Norwegian Map Authority administers a database of all Norwegian buildings, called "The Matrix", where all buildings are represented by a set of coordinates. This gives two sets of geolocated data, climate indices and buildings. GIS-systems, in our case ArcGIS, facilitate the possibility of joining these datasets to analyse geographically distributed impacts. In detail, the method classifies all the indices in zones according to threat level, and counts the number of buildings in each zone both for historical climate data and future climate data. The threat zones were simply generated by splitting the range of the index in three equal parts. Three 


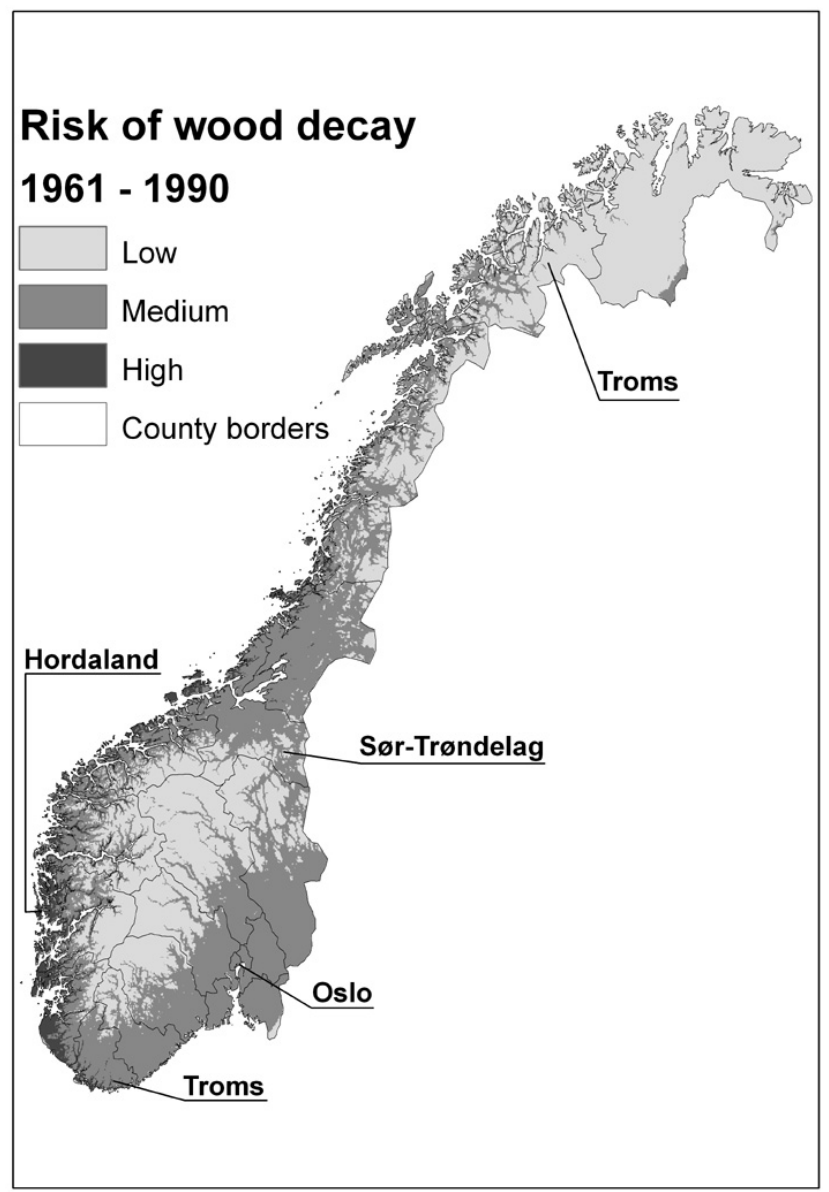

Figure 1. Map of Norway classified in risk of wood decay in a normal climate. Counties selected in Table 1 are marked.

zones are employed for practical reasons, as a balance between detailed results and computing time. To give a more detailed picture, the output results were sorted by counties.

There were some problems with the method. Some of the buildings were geolocated in the wrong UTM zone, thus locating some buildings in Sweden or the north Atlantic. Due to severe time restrictions in the project, there was no time to correct these kinds of error. Even greater uncertainty in the classification is related to how the shoreline was defined in the datasets. The climate grids were trimmed inside the shoreline so that tiles with both sea and land were defined as sea. This resulted in some buildings being defined as situated in the sea. Approximately 300000 buildings ( $8 \%$ ) were unclassified due to these two errors, mostly due to the problem of missing the shoreline. A more thorough description of the method is described in Almås et al. (2011).

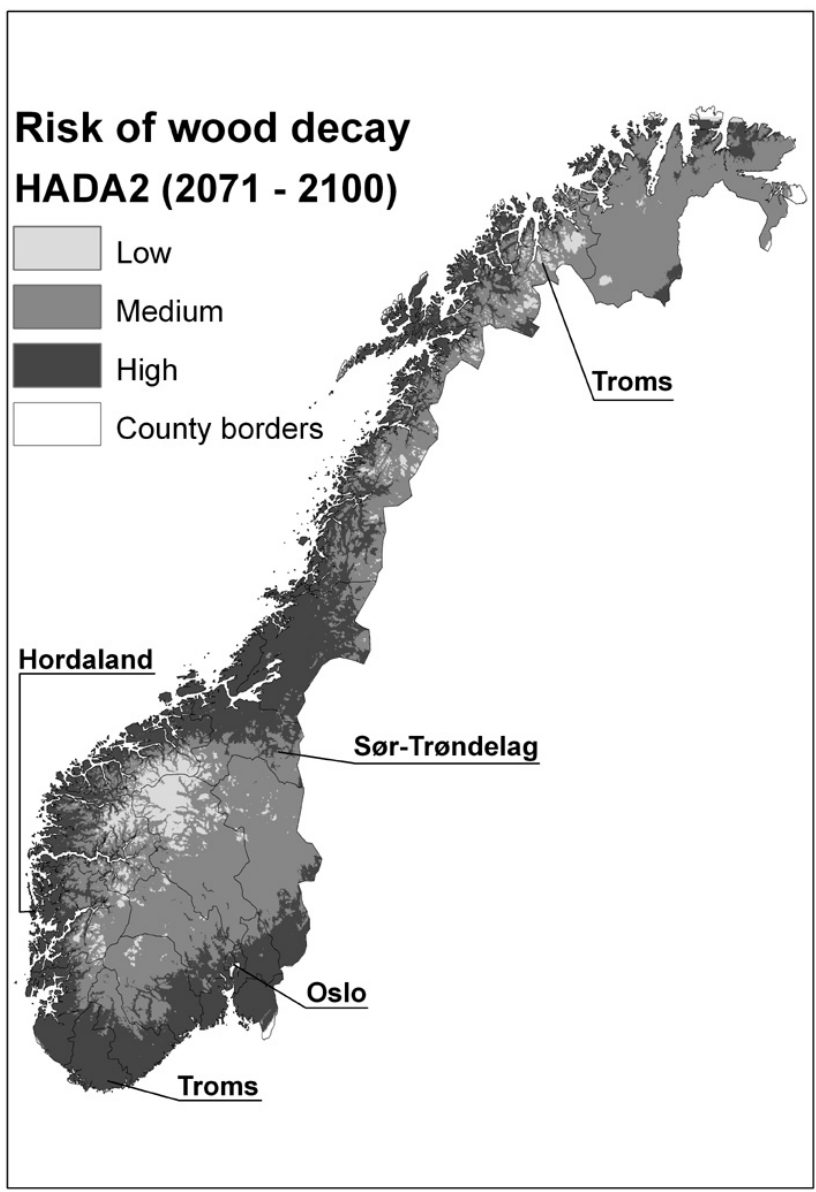

Figure 2. Map of Norway classified in risk of wood decay in future climate, based on projections by the Hadley Centre and scenario A2. Counties selected in Table 1 are marked.

\section{Results}

Some of the indices used in this work are more robust than others. One of the strongest indices in this study is the risk of wood decay. Figure 1 shows a map of Norway classified in three zones of wood decay risk for the normal period 19611990. Figure 2 shows the risk of wood decay at the end of the century according to the projection by the Hadley Centre and scenario A2. Figure 3 shows a comparison of the number of houses in different risk classes based on historical (1961-1990) and future climate data (2071-2100) on a national level. The future climate is emission scenario A2 calculated with the model of the Hadley Centre, and downscaled at the Norwegian Meteorological Institute. Numbers of buildings on a national level in each zone are shown in Fig. 3, while numbers (in thousands) for selected counties are shown in Table 1.

Risk of frost decay is an index giving the risk for frost decay of mineral materials, developed by Lisø et al. (2006). A comparison of present and future risk of frost decay shows 
Table 1. Number, in thousands, of buildings in wood decay risk zones for selected counties in Norway. Upper number is the normal climate (1961-1990), and lower number is projected climate (20712100).

\begin{tabular}{llllll}
\hline County & Period & Un. & Low & Med. & High \\
\hline Oslo & Normal & 2 & 0 & 126 & 0 \\
& HADA2 & 3 & 0 & 0 & 125 \\
\hline Vest Agder & Normal & 11 & 2 & 78 & 30 \\
& HADA2 & 12 & 0 & 0 & 108 \\
\hline Hordaland & Normal & 34 & 3 & 35 & 192 \\
& HADA2 & 35 & 0 & 10 & 220 \\
\hline \multirow{2}{*}{ Sør - Trøndelag } & Normal & 9 & 6 & 184 & 25 \\
& HADA2 & 9 & 0 & 25 & 190 \\
\hline \multirow{2}{*}{ Troms } & Normal & 18 & 11 & 82 & 0 \\
& HADA2 & 20 & 0 & 13 & 78 \\
\hline
\end{tabular}

\section{Number of buildings in Norway in each class of wood decay risk.}

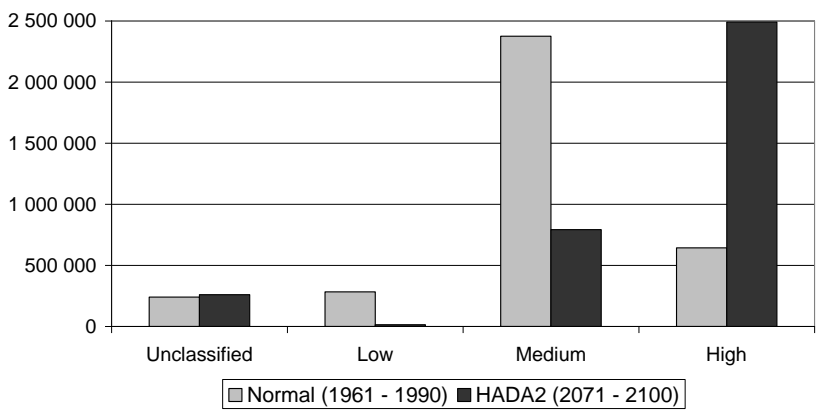

Figure 3. Number of buildings in Norway in normal climate and future climate according to scenario A2. Normal climate in grey and future climate in black.

a clear decrease. This decrease in vulnerability prompted the decision to not count the buildings for this index, due to the current building practices being robust to future climate.

A new index was also examined in this work: Wet Winter precipitation. This index indicates the risk of a snow covered roof being hit by rainfall. The potential impacts are a sudden increase in snow load and water penetrating cracks in the roofing. The index had one major weakness; information about previous snow cover on roofs was not available. This error had to be compensated for manually, resulting in an estimate of 600000 buildings in Norway being affected by increased risk of Wet Winter precipitation.

\section{Discussion}

Multiple dimensions can be analysed to estimate the vulnerability of the Norwegian built environment. We have chosen to estimate the numbers of buildings affected by various climate parameters in combination with a SINTEF Building and Infrastructure survey of reported damage to the present Norwegian building stock (Ingvaldsen, 2001 and Lisø, 2006). The results clearly indicate that precipitation, in combination with other elements, is the main threat to the built environment, both in present and future climates. This knowledge gave a sound platform for advice on how to prepare the buildings for the future. The main advice is:

- carry out more frequent inspections and maintenance;

- use robust construction and detail solutions, components, and building materials with proper documentation of abilities to withstand the challenges of different climate zones of Norway (geographically differentiated building solutions).

Edited by: J. Prior

Reviewed by: two anonymous referees

\section{SC $\mid \operatorname{nat}^{\mathbf{T}} \begin{aligned} & \text { The publication of this article is sponsored } \\ & \text { by the Swiss Academy of Sciences. }\end{aligned}$}

\section{References}

Almås, A., Øyen, C. F., and Hygen, H. O.: An approach to impact assessments of buildings in a changing climate, Build. Res. Inf., 39, 227-238, 2011.

Engen-Skaugen, T., Haugen, J. E., and Tveito, O. E.: Temperature scenarios for Norway: from regional to local scale, Clim. Dynam., 29, 441-453, doi:10.1007/s00382-007-0241-1, 2007.

Ingvaldsen, T.: Skader på bygg: Grunnlag for systematisk måling (Building defects: A basis for systematic evaluation, in Norwegian), NBI Project Report 308. Oslo: Norwegian Building Research Institute, 2001.

Lis $\varnothing$, K. R.: Building envelope performance assessments in harsh climates: Methods for geographically dependent design, Doctoral Theses, NTNU, 185 pp., 2006.

Lis $\varnothing$, K. R. , Hygen, H. O., Kvande, T., and Thue, J. V.: Decay potential in wood structures using climate data, Build. Res. Inf., 34, 546-551, 2006.

Lis $\varnothing$, K. R., Kvande, T., Hygen, H. O., Thue, J. V., and Harstveit, K.: Frost decay exposure index for porous, mineral building materials, Build. Environ., 42, 3547-3555, 2007.

NOU: Tilpassing til eit klima i endring. Servicenteret for departementa, Informasjonforvaltning, Oslo, 2010 (in Norwegian).

Rydock, J. P., Lisø, K. R., Førland, E. J., Nore, K., and Thue, J. V.: A driving rain exposure index for Norway, Build. Environ., 40, 1450-1458, 2005. 